\title{
Gas Chromatography-Mass Spectrometry Study from the Leaves Fractions Obtained of Vernonanthura patens (Kunth) H. Rob
}

\author{
Patricia Manzano Santana ${ }^{1}$, Migdalia Miranda ${ }^{2}$, Juan Abreu Payrol ${ }^{2}$, Mario Silva ${ }^{3}$, \\ Víctor Hernández ${ }^{3}$, Esther Peralta ${ }^{1}$ \\ ${ }^{1}$ Escuela Superior Politecnica de Litoral (ESPOL), Prosperina Campus, Guayaquil, Ecuador \\ ${ }^{2}$ Institute of Food and Drugs, University of Havana, Havana, Cuba \\ ${ }^{3}$ School of Natural Sciences and Oceanography, University of Concepción, Concepción, Chile \\ Email: manzanopatricia@hotmail.com,migdamir@hotmail.com,mjsilva@udec.cl
}

Received April 13, 2013; revised May 15, 2013; accepted May 23, 2013

Copyright (C) 2013 Patricia Manzano Santana et al. This is an open access article distributed under the Creative Commons Attribution License, which permits unrestricted use, distribution, and reproduction in any medium, provided the original work is properly cited.

\begin{abstract}
Preliminary phytochemical study of methanol extracts from Vernonanthura patens's leaves located in Marcabelí (El Oro province), Ecuador. The methodology consisted of chromatographic column separations with increasing polarity solvents and the analysis of fractions by Gas Chromatography-Mass Spectrometry coupled system (GC-MS). The structure of 53 compounds was proposed. Analyzed $V$. patens species showed the presence of terpene and aliphatic hydrocarbons, free fatty acids and their methyl and ethyl esters, oxygen sesqui, triterpenoids and sugars. For ecuadorian species, there are no records of chemical studies.
\end{abstract}

Keywords: Vernonanthura patens; Phytochemical Study; Gas Chromatographic-Mass Spectrometry Analysis

\section{Introduction}

Vernonanthura patens (Kunth) H. Rob [Asteraceae]-a wild shrub from South America, is distributed from southern Mexico to Rio de la Plata-Argentina [1,2]. The common name of this species in Ecuador is "laritaco". Traditionally, leaves' decoctions are used to fight malaria, postpartum, stomach problems, skin rashes, diarrhea and as an anthelmintic [3,4]. In Ecuador, V. patens is used to wash wounds, relieve headaches, it is also used as the anti-inflammatory compound and cough suppressant to treat certain types of cancer. It is also reported its use for leishmaniasis [5] and athlete's foot treatment [6]. Despite the complexity of components reported for the genus, there is little information on the species $V$. patens in particular. The earliest information listed on the chemical composition of the species dates from 1975, which only highlights the absence of sesquiterpene lactones in the species which constituted a chemical marker of género [7]. However, in 1986, 10 compounds were identified among those, including sesquiterpene [8], lactones. These were the only previous reports on the chemical composition of the species, none of which grows in Ecuador. The present study was aimed to develop a preliminary phytochemical analysis of methanolic extracts of Vernonanthura patens's leaves, followed by a further fractionation by column chromatography and analysis of the fractions by Gas Chomatograpy-Mass Spectrometry coupled system (GC-MS).

\section{Methods}

Vernonanthura patens adult leaves were collected from plants in vegetative state, during the months of December to February (2009 and 2010), in El Oro province of Ecuador.

Drying of leaves was performed in an oven by recirculating air at $45^{\circ} \mathrm{C}$ for eight hours. Dried leaves were ground in a knife mill to a powder ( $2 \mathrm{~mm}$ of particle diameter), particles.

Sixty-seven grams of the dry drug were extracted by maceration with pure methanol in a closed container and darkness for eight days. The extract was evaporated until dryness in a rotary evaporator and the residue $(7 \mathrm{~g})$ was fractionated by chromatography column packed with activated silica gel (60 to 200 mesh). Hexane, hexane/ ethyl acetate 90:10; hexane/ethyl acetate 80:20 and ethyl acetate, were used as solvent systems. 
The obtained fractions were analyzed by GC-MS, in an Agilent 7890A gas chromatograph, with Agilent 5975 detector (Avondale, PA, USA) equipped with a HP column of $5 \mathrm{~m}$ long $(0.25 \mathrm{~mm}$ diameter and $0.25 \mathrm{~cm}$ internal diameter). The carrier gas was helium and the analytical conditions were: initial temperature: $100^{\circ} \mathrm{C}$ (increasing $8^{\circ} \mathrm{C}$ per minute till $250^{\circ} \mathrm{C}$ final temperature); inlet temperature and mass detector: $250^{\circ} \mathrm{C}$ and $300^{\circ} \mathrm{C}$ respectively. The mass detector was used in scan mode ("scan") with a range of 100 to 400 mass units.

The structural assignments were made by the library database selecting only those structures that reached $90 \%$ or more probability.

Six fractions were analyzed by GC-MS: two hexane fractions ("A" and "B"); two from hexane/ethyl acetate mixture (90:10 and 80:20 respectively); one ethyl acetate fraction and the insoluble residue from the initial methanol extract.

\section{Results}

From the A hexane extract, the structures of 29 compounds were assigned (Figure 1, Table 1) and from B hexane extract there were 8 compounds (Figure 2, Table 2).

From the ethyl acetate 90:10 and 80:20 mixes the structures of 12, 10 and 2 compounds were proposed respectively (Figures 3 and 4, Table 3). In the ethyl acetate fraction 4 compounds were identified (Figure 5), while in the alcoholic residue we identified 9 compounds (Figure 6, Table 4).

Twenty-nine and eight compounds were proposed by CG-MS in hexane fractions "A" (Figure 1, Table 1) and "B" (Figure 2, Table 2) respectively. Analysis of fractions eluted with hexane/ethyl acetate mixtures (90:10 and 80:20) and ethyl acetate showed 10, two and seven compounds respectively (Figures 3-5; Table 3). Seven structures were tentatively assigned when methanol residue of initial extract was studied (Figure 5 and Table 4).

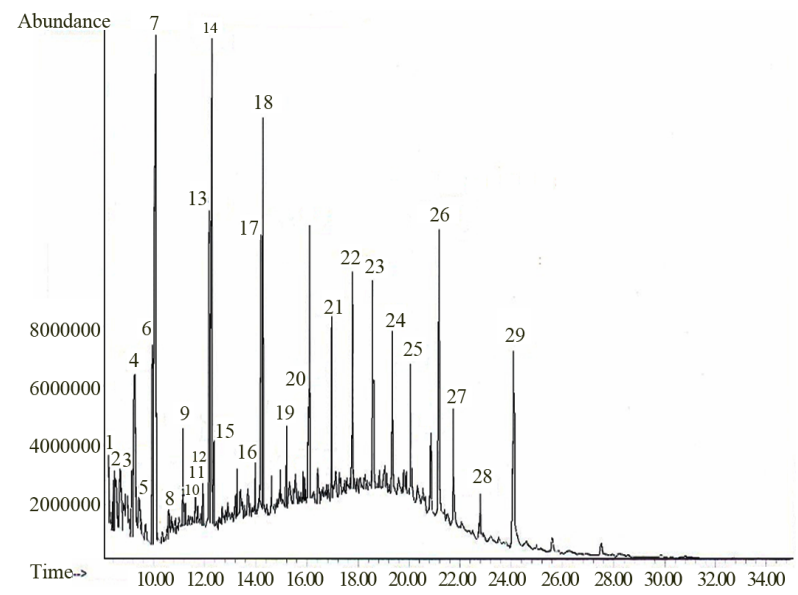

Figure 1. Analytical gas chromatogram of the $\mathrm{A}$ hexane fraction.

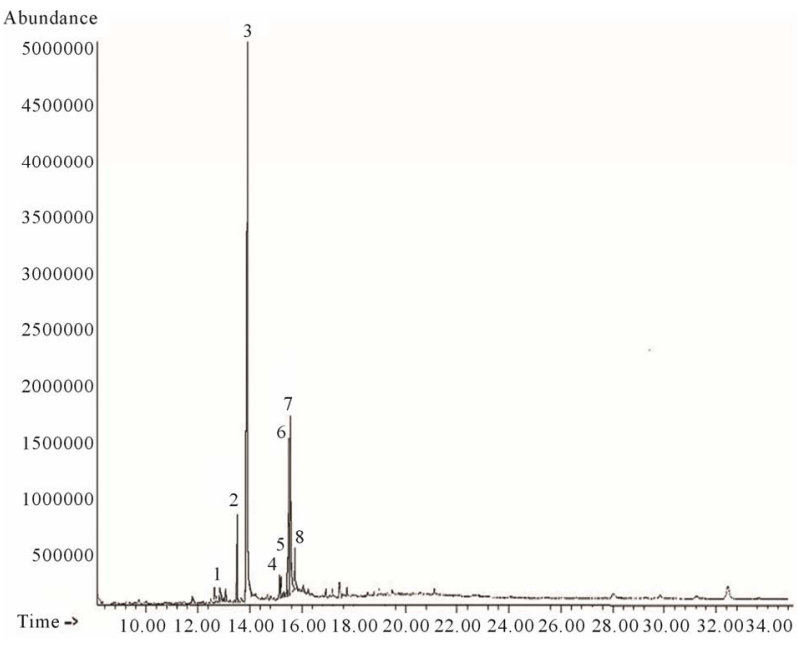

Figure 2. Analytical gas chromatogram of the B hexane fraction.

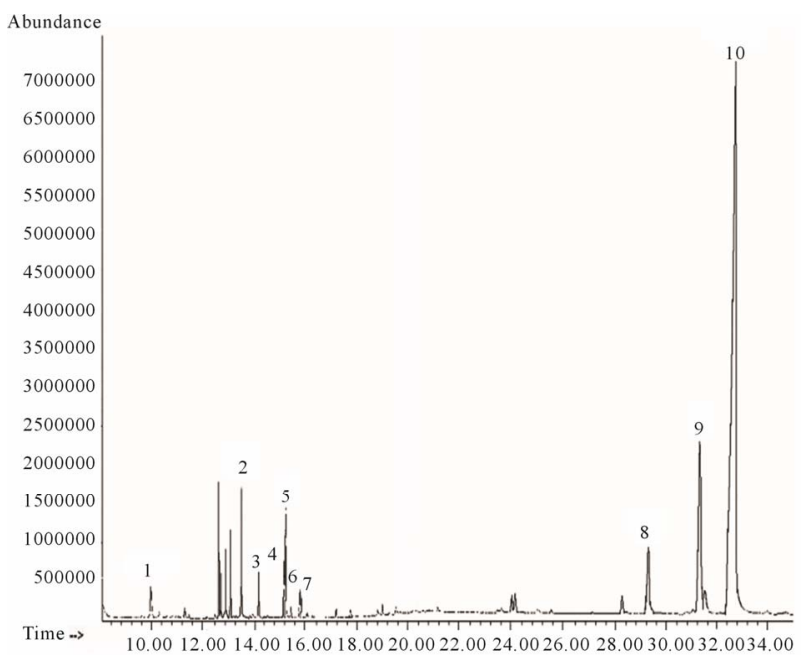

Figure 3. Analytical gas chromatogram of hexane-ethyl acetate 90:10 fractions.

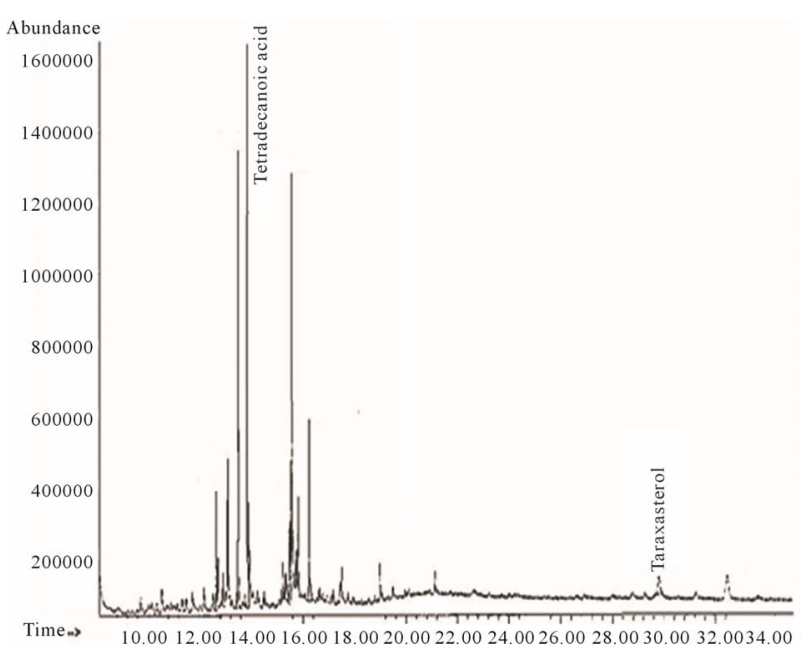

Figure 4. Analytical gas chromatogram of hexane-ethyl acetate $80: 20$ fraction. 
Table 1. Compounds identified in the A hexane fraction.

\begin{tabular}{|c|c|c|c|}
\hline Peak & Tr Min. & Compound & Abundance \% \\
\hline 1 & 8.435 & $\alpha$-Caryophyllene (sesquiterpene) & 1.67 \\
\hline 2 & 8.678 & $\begin{array}{l}\text { Napthalene, 1,2,3,4,4a,5,6,8a-octahydro-7-methyl-4-methylene-1-(1-methylethyl)-(1 } \alpha, 4 \mathrm{a} . \alpha, 8 \mathrm{a} . \alpha \text { ) } \\
\text { (bicyclic sesquiterpene, type selinene) }\end{array}$ & 2.10 \\
\hline 3 & 9.156 & $\begin{array}{l}\text { Naphthalene, 1,2,4a,5,6,8-hexahydro-4,7-dimethyl-1-(1-methylethyl) } \\
\text { (bicyclic sesquiterpene, type selinene isomer) }\end{array}$ & 1.69 \\
\hline 4 & 9.234 & $\begin{array}{l}\text { Naphthalene, 1,2,3,5,6,8a-hexahydro-4,7-dimethyl-1-(1-methylethyl) } \\
\text { (bicyclic sesquiterpene, type selinene isomer) }\end{array}$ & 5.73 \\
\hline 5 & 9.426 & $\begin{array}{l}\text { Naphthalene, 1,2,4a,5,6,8a-hexahydro-4,7-dimethyl-1-(1-methylethyl)-[1S-(1. } \alpha, 4 \mathrm{a} . \beta, 8 \mathrm{a} . \alpha \text { )] } \\
\text { (bicyclic sesquiterpene, type selinene isomer) }\end{array}$ & 1.49 \\
\hline 6 & 9.950 & 2-Tetradecene, (E)- & 4.81 \\
\hline 7 & 10.090 & Tetradecane & 16.82 \\
\hline 8 & 10.583 & 2,6,10-Trimethyl-pentadecane & 0.79 \\
\hline 9 & 11.153 & 2,6,11-Trimethyl-pentadecane & 1.40 \\
\hline 10 & 11.226 & 2,6,10-Trimethyl-dodecane & 0.63 \\
\hline 11 & 11.646 & Tritetracontane & 0.57 \\
\hline 12 & 11.937 & Hexadecane & 0.60 \\
\hline 13 & 12.191 & 1-Octadecene & 6.41 \\
\hline 14 & 12.295 & Heptadecane & 10.82 \\
\hline 15 & 12.357 & 4-Methyl-heptadecane & 0.92 \\
\hline 16 & 13.976 & Octadecane & 0.56 \\
\hline 17 & 14.199 & 3-Eicosene & 3.68 \\
\hline 18 & 14.272 & Eicosane & 5.68 \\
\hline 19 & 15.180 & Heneicosane & 0.97 \\
\hline 20 & 16.031 & 1-Docosene & 1.19 \\
\hline 21 & 16.944 & Nonadecane & 2.05 \\
\hline 22 & 17.769 & Tetracosane & 2.68 \\
\hline 23 & 18.563 & 11-Decyl-tetracosane & 2.86 \\
\hline 24 & 19.325 & 9-Octyl-heptadecane & 2.50 \\
\hline 25 & 20.057 & 5,14-Dibutyl-octadecane & 1.55 \\
\hline 26 & 21.157 & Squalene & 4.51 \\
\hline 27 & 21.738 & Nonacosane & 1.98 \\
\hline 28 & 22.791 & 11-Pentyl-heneicosane & 1.03 \\
\hline 29 & 24.104 & Hentriacontane & 6.03 \\
\hline
\end{tabular}

\section{Discussion}

The hexane fraction " $A$ " contained 29 hydrocarbons compounds (Figure 1, Table 1). Five of the identified compounds were sesquiterpenes, one was a triterpene and the rest were aliphatic of high molecular mass, which were classified as fatty compounds [9]. The most abun- dant compounds were tetradecane (peak 7) and heptadecane (peak 14); hentriacontano, 1-octadecene, eicosane, an isomer of selinene (peak 4), 2-tetradecene and squalene, showed a relative abundance.

The hexane fraction "B" consisted of mainly fatty acids (Figure 2, Table 2). The most preponderant compound was tetradecanoic acid (peak 3), in correspondence with 


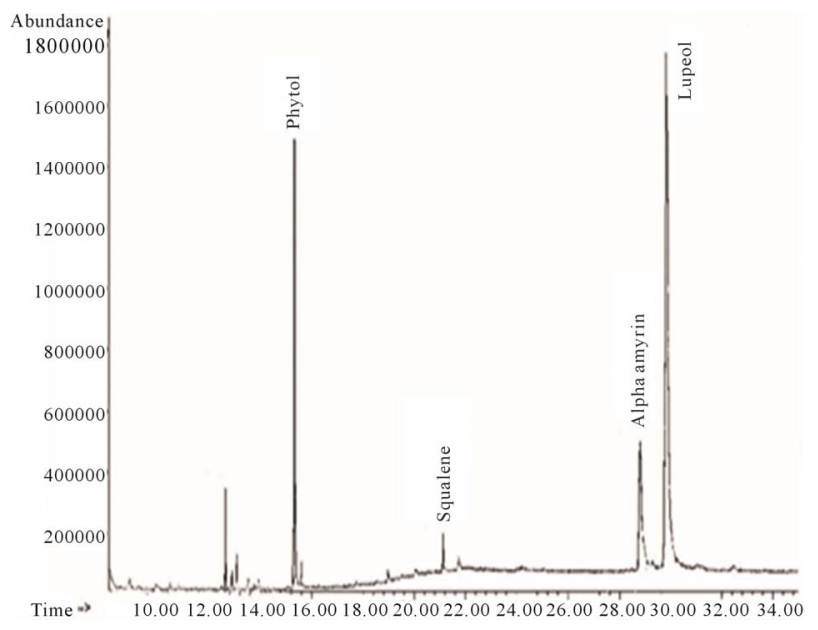

Figure 5. Chromatogram of the ethyl acetate fraction.

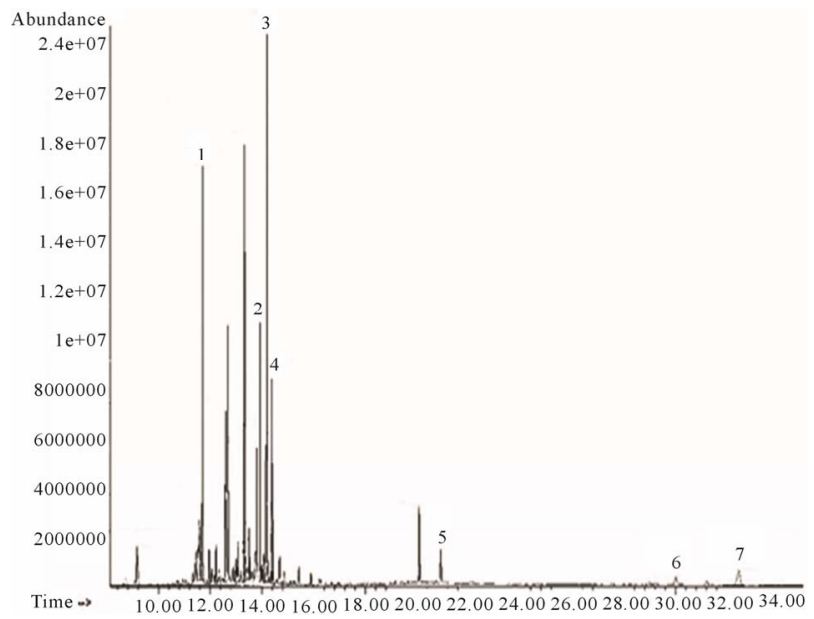

Figure 6. Chromatogram of the ethyl acetate fraction.

Table 2. Compounds identified in the B hexane fraction.

\begin{tabular}{|c|c|c|c|}
\hline Peak & $\begin{array}{c}\text { Tr } \\
\text { Min }\end{array}$ & Compound & $\begin{array}{c}\text { Abundance } \\
\%\end{array}$ \\
\hline 1 & 12.835 & Pentadecanoic acid & 1.69 \\
\hline 2 & 13.514 & Hexanoic acid methyl ester & 5.42 \\
\hline 3 & 13.898 & Tetradecanoic acid & 56.78 \\
\hline 4 & 15.143 & 9,12-Octadecadienoic acid-methylester & 1.63 \\
\hline 5 & 15.206 & 9,12,15-Octadecatrienoic acid-1-ol & 1.17 \\
\hline 6 & 15.496 & 9.12-Octadecadienoic acid & 10.81 \\
\hline 7 & 15.5599 & ,12,15-Octadecatrienoic acid-methyl ester & 13.78 \\
\hline 8 & 15.725 & Octadecanoic acid & 2.59 \\
\hline
\end{tabular}

tetradecane presence as majority hydrocarbon in hexane fraction " $A$ ". There was also a relative abundance of diand tri-unsaturated fatty acids as methyl esters forms. Presence of methyl esters is characteristic of some Asteraceae species.
Table 3. Compounds identified in hexane-ethyl acetate 90:10 fractions.

\begin{tabular}{|c|c|c|c|}
\hline Peak & $\begin{array}{c}\text { Tr } \\
\text { Min. }\end{array}$ & Compound & $\begin{array}{c}\text { Abundance } \\
\%\end{array}$ \\
\hline 1 & 10.001 & Caryophyllene oxide & 1.25 \\
\hline 2 & 13.514 & Hexadecanoic acid methyl ester & 2.63 \\
\hline 3 & 14.178 & Hexadecanoic acid ethyl ester & 0.81 \\
\hline 4 & 15.143 & 9,12-Octadecadienoic acid methyl ester & 0.93 \\
\hline 5 & 15.211 & 9,12,15-Octadecatrienoic acid methylester & 2.11 \\
\hline 6 & 15.750 & 9,12-Octadecadienoic acid ethyl ester & 0.48 \\
\hline 7 & 15.813 & 9,12,15-Octadecatrienoic acid ethylester & 0.59 \\
\hline 8 & 29.277 & 3-Friedelanon-8-en & 4.54 \\
\hline 9 & 31.270 & 3-Acetate-12-oleaneno & 12.31 \\
\hline 10 & 64.05 & Lupeol acetate & 64.05 \\
\hline
\end{tabular}

Table 4. Compounds identified in methanol extract residue.

\begin{tabular}{cccc}
\hline Peak & Tr min & Compound & Abundance \% \\
\hline 1 & 11.689 & Xylitol & 13.08 \\
2 & 13.919 & D-mannitol & 8.31 \\
3 & 14.168 & Inositol & 19.69 \\
4 & 14.370 & D-glucose & 5.35 \\
5 & 20.918 & Stigmasterol & $\mathrm{t}$ \\
6 & 30.014 & Lupenone & $\mathrm{t}$ \\
7 & 32.479 & Lupeol acetate & $\mathrm{t}$ \\
\hline
\end{tabular}

Methyl and ethyl esters of fatty acids were also detected in the hexane/ethyl acetate 90:10 fraction (Figure 3, Table 3), Three of them were already assigned in the hexane fractions. High abundance of a sesquiterpenoid (caryophyllene oxide) and two triterpenoid acetates was observed, although the most abundant compound was $\mathrm{Lu}-$ peol acetate. It should be noticed the presumable presence of friedelanon, which has been reported in other species of Vernonanthura genus [8].

Two compounds structures were assigned by analysis of the hexane/ethyl acetate 80:20 fraction (Figure 4). The most abundant was tetradecanoic acid, which was also detected in the hexane fraction "B". The other proposed compound was taraxasterol, a triterpene.

Four terpene compounds were proposed from the ethyl acetate fraction (Figure 5): A diterpene (phytol), and three triterpenes (squalene, $\alpha$-amyrin and lupeol). Squalene was already assigned in the hexane fraction "A", and lupeol was the most abundant compound of the ethyl acetate fraction.

The residue of the initial methanol extract was silan- 
ized for its chromatographic analysis. GC-MS analysis (Figure 6, Table 4) showed the presence of carbohydrate-like compounds at the first 15 minutes retention time. Xylitol, D-mannitol, D-glucose and inositol, the most abundant compound (peak 3), were the only structures which could be assigned. The compounds exceeded 15 minutes retention time were triterpenoids; both of them (lupenone and stigmasterol) were assigned for the first time in this study.

Fifty-three compounds were proposed in this study of methanol extract of Vernonanthura patens' leaves, which constitute the first report of its chemical composition.

\section{Conclusions}

The $V$. patens species, was shown in its leaves' composition, terpene and aliphatic hydrocarbons, free fatty acids and their methyl and ethyl esters, oxygen sesqui and triterpenoids and sugars. Sesquiterpene lactones reported for the plant species were not detected.

Further researches are in need to determine the compounds which are responsible for the biological activity previously reported for this plant species.

\section{Acknowledgements}

The authors thank SENESCYT for partial financial support of this work.

\section{REFERENCES}

[1] A. J. Vega and M. Dematteis, "Analysis of Pollen Morphology in the Genus Vernonanthura (Vernonieae, Asteraceae)," Project Research and Development, General Secretariat of Science and Technology, Universidad Nacional del Nordeste, PI 44/2007, UNNE-CONICET. Scientific and Technological Communities, 2009.
[2] A. M. Juárez, J. Ayasta, E. R. Aguirre and E. F. Rodriguez, "The Oscurana (Cajamarca), One More to Preserve Relict Forest in the Western Andean Slopes of Northern Peru. Relict Forests of NW Peru and SW Ecuador," Peruvian Journal of Biology, Vol. 12, No. 2, 2005, pp. 289-298.

[3] O. Acuña, “Assessment of Physical and Chemical Characteristics of Species Ligno-Cellulosic and Agro-Products in Pulping and Papermaking," First National Meeting of Producers and Artisans from Natural Fibers, Technical Reports, Ibarra, 2000.

[4] S. Blair, "Antimalarial Plants of Tumaco: Colombian Pacific Coast,” 1st Edition, University of Antioquia, Medellín, 2005, pp. 84-87.

[5] M. Gacheta, J. Salazar, M. Kaiserc, R. Brunc, H. Navarrete, R. Muñoz, R. Bauer and W. Schühlya, “Assessment of Anti-Protozoal Activity of Plants Traditionally Used in Ecuador in the Treatment of Leishmaniasis," Journal of Ethnopharmacology, Vol. 128, No. 1, 2010, pp. 184-197. doi:10.1016/j.jep.2010.01.007

[6] C. Valadeau, A. Pabon, E. Deharo, J. Albán-Castillo, Y. Estévez, F. Lores, R. Rojas, D. Gamboa, M. Sauvain, D. Castillo and G. Bourdy, "Medicinal Plants from the Yanesha (Peru): Evaluation of the Leishmanicidal and Antimalarial Activity of Selected Extracts," Journal of Ethnopharmacology, Vol. 123, No. 3, 2009, pp. 413-422. doi:10.1016/j.jep.2009.03.041

[7] T. J. Mabry, Z. Abdel-Baset and W. G. Padolina, "Systematic Implications of Flavonoides and Sesquiterpene Lactones in Species of Vernonia,” Biochemical Sistematics and Ecology, Vol. 2, No. 3-4, 1975, pp. 185-192. doi:10.1016/0305-1978(75)90060-5

[8] J Jakupovic and G. Schmedia-Hirschmann, "Hirsutinolides, Glaucolides and Sesquiterpene Lactones in Species of Vernonia Species,” Phytochemistry, Vol. 25, No. 1, 1986, pp. 145-158. doi:10.1016/S0031-9422(00)94520-5

[9] D. Marcano and H. Masahisa, "Organic Phytochemistry. Council of Scientific and Humanistic Studies," Journal of Natural Products, Vol. 66, No. 9, 2003, pp. 1298-1298. 